\title{
Taxonomic Notes on Mystus Species of Northern Kerala
}

\section{Dr. Mathews Plamoottil*}

Department of Zoology, Government College, Chavara Kollam District, Kerala, India

\begin{abstract}
Systematic studies conducted on Mystus species of northern Kerala are very rare. It is due the taxonomic ambiguity which had existed in many species of this genus? To solve this dilemma, during this study, all Mystus species were collected from their type localities and taxonomically analysed. Examination of meristic, metric and major morphometric characters helped to prove the identity of all Mystus species of these regions.
\end{abstract}

Keywords: Wayanad; Trichur; Biodiversity; Catfishes; Bagrids

Abbreviations: D: Dorsal fin rays; P: Pectoral fin rays; V: Ventral fin rays; A: Anal fin rays; C: Caudal fin rays; DspT: Dorsal Spine Teeth; PspT: Pectoral Spine Teeth; HW: Head Width; BDD: Body Depth at Dorsal fin origin; BDA: Body Depth at Anal Fin orign; BWD: Body Width at Dorsal fin; BWA: Body Width at Anal fin; PRD Pre Dorsal Distance; POD: Post Dorsal Distance; PRP: Pre Pectoral distance; PRPL: Pre Pelvic distance; PRA: Preanal distance; LRD: Length of Rayed Dorsal Fin; LAD: Length of Adipose Dorsal fin; LP: Length of Pectoral fin; LPL: Length of Pelvic fin; LA: Length of Anal Fin; LDSP: Length of Dorsal Spine; LPSP: Length of Pectoral Spine; LUCL: Length of Upper Caudal Lobe; LLCL: Length of Lower Caudal Lobe; LBRD: Length of Base of Rayed Dorsal; LBAD: Length of Base of Adipose Dorsal; LBA: Length of Base of Anal; LBC: Length of Base of Caudal fin; LCP: Length of Caudal Peduncle; DCP: Depth of Caudal Peduncle; WCP: Width of Caudal Peduncle; DPPL: Distance from Pectoral to Pelvic fin; DPL-A: Distance from Pelvic to Anal fin; DA-C: Distance from Anal to Caudal fin; DAD-C: Distance from Adipose Dorsal to Caudal fin; DRD- AD: Distance from Rayed Dorsal to Dipose Dorsal; DAV: Distance from Anal to Vent; DVV: Distance from Ventral to Vent; HD: Head Depth; HW: Head Width; DOST: Distance from Occiput to Snout; DOD: Distance from Occiput to Dorsal fn; LFG: Length of Frontal Groove; LOP: Length of Occipital Process; PORL: Post Orbital Length; STL: Snout Length; ED: Eye Diameter; IOW: Interorbital length; INW: Internarial Width; STL: Snout Length; WGM: Width of Gape of Mouth; LMB: Length of Maxillary Barbels; LNB: Length of Nasal Barbels; LOMB: Length of Outer Mandibular Barbells; LIMB: Length of Inner Mandibular Barbells.

\section{Introduction}

Mystus scopoli is the most common Bagrid fish genus in India and adjacent countries. These small edible catfishes occur in most inland water bodies of Kerala and Tamil Nadu. They can be diagnosed by the presence of cephalic groove, occipital process, sub equal jaws, four pairs of barbels, anterior rayed dorsal fin and posterior adipose fin. Fishes of the genus also bear 11-30 gill rakers on the first gill arch, a thin needle-like first infra orbital, 37-46 vertebrae and twisted and thickened metapterygoid loosely attached to the quadrate $[1,2]$.

Mystus oculatus (Valenciennes) [3], M. montanus (Jerdon) [4], M. malabaricus (Jerdon) [4], M. armatus (Day) [5], M. canarensis (Day, Grant) [5,6], M. heoki Plamoottil and Abraham [7], M. indicus Plamoottil and Abraham [7], M. menoni Plamoottil and Abraham [8], M. keralai Plamoottil and Abraham [9] and M. catpogon Plamoottil [10] are the Mystus species described from inland water bodies of Kerala. Of these, first four were described from northern parts of Kerala. During the last five years many taxonomic studies $[11,12]$ and many new descriptions [13-15] and redescriptions [16] were conducted on catfishes of central parts of Kerala; but very rare serious systematic studies conducted on Mystus species of northern Kerala after Valenciennes [3], Jerdon [4] and Day $[5,17,18]$; it may be due to the ambiguity which had existed in many species of this genus. Type specimens of most of these species were unavailable in museums; specimens collected from their type localities are also lacking for comparative studies. During this study, this author could collect topotype specimens of all Mystus species of northern Kerala. It is an endeavor to trace out the systematic details of species of this genus to solve the taxonomic confusion.

\section{Materials and Methods}

Fishes were collected using gill net and cast net. Clear images were taken and essential topographic details were noted. Live specimens are cleaned with water and preserved in $10 \%$ formalin. They were taxonomically identified using relevant literature. Methods used are those of Jayaram $[19,20]$ and measurements follow standard taxonomic practices. Body depth and body width were measured both at dorsalfin origin and anus, vertically from dorsal fin origin to belly and from anus to dorsum, respectively. After taxonomic studies specimens were deposited in Zoological Survey of India museums at Kolkata.

\section{Results and Discussion}

Five Mystus species (Figure 1) were collected from various sites of northern Kerala. They were Mystus seengte, M. malabaricus, M. montanus, M. oculatus and Mystus armatus. First three were collected from Wayanad and remaining ones were from Trichur. Taxonomic analysis revealed the identity of each of these species.

\section{Mystus malabaricus (Jerdon)}

Bagrus malabaricus Jerdon [4], Madras Jour Lit \& Sci 15: 338 (type locality: Mountain streams of Malabar).

Names: regional names- Kallenkoori, Kotti; common names Jerdon's Mystus; synonyms: Bagrus malabaricus, Macrone malabaricus, Mystus maydelli

*Corresponding author: Dr. Mathews Plamoottil, Professor, Department of Zoology, Government College, Chavara Kollam District, Kerala, India, Tel: 0476268 0736; E-mail: mathewsplamoottil@gmail.com

Received April 29, 2017; Accepted July 25, 2017; Published July 27, 2017

Citation: Plamoottil M (2017) Taxonomic Notes on Mystus Species of Northern Kerala. J Aquac Res Development 8: 495. doi: 10.4172/2155-9546.1000495

Copyright: @ 2017 Plamoottil M. This is an open-access article distributed under the terms of the Creative Commons Attribution License, which permits unrestricted use, distribution, and reproduction in any medium, provided the original author and source are credited. 


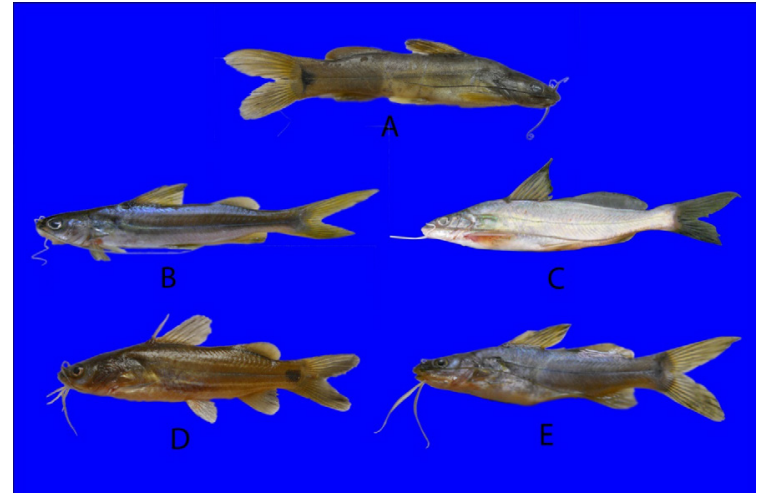

Figure 1: Mystus species of northern Kerala: (A). Mystus malabaricus; (B). $M$ oculatus; (C). M. seengtee; (D). M. montanus; (E). M. armatus.

Diagnosis: Body elongate; dorsal and ventral profiles nearly straight; maxillary barbels reach to middle or end of pelvic fins; cephalic fontanel single, shallow and never reach to occiput; occipital process short and it do not reach dorsal front; the former cannot be seen externally as predorsal region is covered by a thick layer of flesh; caudal lobes rounded.

Meristic counts: D- I, II, 6-7; P- I, 7-8; V- i, 5; A- iii,8; C- 17; DspTNil; PspT- 7-13.

Metric characters: TL (mm)- 92.0-127.0: SL (mm): 71.5- 102.0; \% SL: HL- 23.8- 24.7; HD- 13.2- 14.4; HW- 16.7- 17.8; BDD- 19.0- 20.5; BDA- 16.8- 17.8; BWD- 15.2- 16.8; PRD-34.8- 37; POD- 64.8- 67.1; PRP- 20.4- 22.3; PRPL- 49.0- 51.0; PRA- 67.1- 69.4; LRD- 17.6- 19.8; LAD- 4.1- 5.7; LP- 15.7- 17.8; LPL- 13.7- 15.3; LA- 11.2- 15.1; LDSP9.8- 10.8; LPSP- 12.0- 13.3; LBRD- 15.3- 16.2; LBAD- 27.3- 30.7; LBA- 13.6- 15.3; LBC- 15.3-16.5; LCP- 16.4- 18.5; DCP- 13.3- 15.5; WCP- 3.0- 4.7; DP-PL- 28.3- 31.7; DPL- A- 19.6-20.1; DA-C- 30.0-3.6; DAD-C- 12.0- 14.2; DRD- AD- 8.2- 11.3; DAV- 3.6-5.1; DVV- 15.316.8; HL (mm)- 17.5- 24.5; HD- 53.7- 60.0; HW- 68.3- 72.2; DOST83.7-87.8; DOD- 61.1-65.8; LFG- 55.6-68.3; PORL- 41.5-48.9; STL29.3- 34.7; ED- 23.7- 29.3; IOW- 26.8- 30.0; INW- 18.4- 22.2; STL 29.3- 34.7-; WGM- 40.0- 44.4; LMB- 253.2- 291.7-; LNB- 61.2- 75.0; LOMB- 110.2- 126.7; LIMB- 78.8- 88.6.

Other morphological characters: Nasal barbels never reach occiput, it reaches a middle point between occiput and orbit; outer mandibulars reach to tip of pectorals; occipital process connected to dorsal front by an interneural shield; tip of rayed dorsal reaches to base of adipose dorsal front; any other fins touch each other; dorsal spine smooth both internally and externally; anal fin inserted considerably behind anal opening; upper caudal lobe longer than lower one. Sensory organs distinctly seen on lateral line. Color: body greenish; eyes blackish blue.

Distribution and Habitat: Kerala, Karnataka and Tamil Nadu; found in shallow hill streams with rocky bottom.

\section{Mystus montanus (Jerdon)}

Babrus montanus, Jerdon [4], Madras J Lit Sci 15: 337 (Type locality: Mananthavady, Wayanad)

Names: Regional name: Kotti, Kallenkoori; common name: Wayanad Mystus; Synonyms: Bagrus montanus, Macrones montanus.

Diagnosis: Barbels are short, weak and feeble; cephalic groove shallow and peripheral; it never reaches occiput; occipital process reaches basal bone of dorsal fin; dorsal spine not attached with rest of dorsal rays; adipose fin short; inter dorsal distance greater; pectoral fin with 6 branched rays; caudal fin with 15 principal rays; caudal lobes nearly rounded; a distinct oval black spot present on caudal base; humeral color spot diffuse.

Meristic counts: D- I, 7; P- I, 6; V- i, 5; A- iii, 8; C- 15; DspT- 8; PspT- 14,15

Metric characters: TL-86.3; SL- 67.5; \% SL: HL-28.1; HD- 17.0; HW- 20.7; BDD- 23.0; BDA- 19.3; BWD-17.0; PRD- 40.0; POD- 64.4; PRP- 23.7; PRPL- 50.4; PRA- 72.6; LRD- 20.4; LAD- 6.0; LP- 17.8; LPL- 13.3; LA- 15.6; LDSP- 10.4; LUCL- 27.8; LLCL- 25.2; LBRD16.3; LBAD- 21.5; LBP- 5.6; LBPL- 4.4; LBA- 11.1; LBC- 14.5; LCP14.8; DCP- 11.9; WCP- 5.6; DP-PL- 28.1; DPL- A- 22.2; DA-C- 28.1; DAD-C- 14.7; DRD- AD- 8.9; DAV- 4.4; DVV- 15.6; HL (mm)- 19.0; \% HL: HD- 60.5; HW- 73.7; DOST-85.3; DOD- 52.6; LFG- 46.8; LOP36.8; PORL- 47.4; STL- 73.7; ED- 26.3; IOW- 33.2; INW- 18.4; STL30.5; WOP- 15.8; WGM- 44.7; LMB- 226.3; LNB- 57.9; LOMB-100.0; LIMB- 63,2

Other morphological characters: Maxillary barbels reach up to tip of ventral fin; nasals never reach occiput; outer mandibulars reach half-length of pectoral fin; inner mandibluars never reach pectoral fin base; orbit diameter less than inter orbital width; upper jaw projects out when mouth is closed; highest point of adipose fin not above the general height of dorsal surface; adipose dorsal fin with two parts; basal part thick but narrow; distal part higher, thin and is like a flap; dorsal spine thin; a few serrations present on the outer margin of dorsal spine; dorsal surface of head smooth as it is covered with a thin skin; anterior nostrils located at the tip of snout.

Colour: Back and upper lateral sides brown; ventro lateral sides whitish yellow; eyes blue colored.

Distribution and habitat: Wayanad and Karnataka. Found in shallow hill streams with rocky bottom.

\section{Mystus armatus (Day)}

Hypselobagrus armatus, Day [5], Proceedings of Zoological society of London: 289. (Type locality: 'Cochin, Malabar'- Trichur)

Names: regional names: puzhukkoori, kotti, chillankoori; common name- Kerala Mystus; synonyms: Hypselobagrus armatus, Macrones armatus.

Diagnosis: Mystus armatus differs from its congeners in having a comparatively long head, dorsal surface of which is rugose, median longitudinal groove with double cephalic fontanels, the posterior fontanel spindle shaped, elongated maxillaries which reach near to caudal base and long pelvic fin which reach anal fin origin; Mystus armatus can further differentiated from its relative species in lacking any distinct colour spots on humeral and caudal regions.

Meristic counts: D- II, 7; P- I, 9; V- i, 5; A- iii, 8; C- 19; DspT- 6; PspT- 10- 14.

Metric characters: TL (mm) - 84.8-88.7; SL (mm) - 69.7- 84.8; \% SL: HL- 25.5- 26.0; HD- 16.0- 17.2 ; HW- 18.7- 19.5; BDD- 20.1- 22.4; BDA- 18.7- 18.9; BWD- 17.2- 17.7; BWA- 10.6- 11.5; PRD- 36.0- 37.3; POD- 66.0- 66.5; PRP- 23.6- 23.8; PRPL- 49.4- 49.6; PRA- 67.8- 70.0; LRD- 22.4- 25.5; LAD- 4.7- 5.6; LP- 20.0- 21.5; LPL- 16.5- 18.3; LA17.2- 18.2 ; LDSP- 11.0- 12.7; LPSP- 18.4- 19.0; LUCL- 30.1- 33.0; LLCL25.0- 28.9; LBRD- 16.5- 17.1; LBAD- 27.0- 28.9; LBA- 12.8- 14.3; LBC14.3- 14.5; LCP- 18.9- 19.8; DCP- 11.5- 11.8; WCP- 3.5- 5.7; DP-PL- 
28.3- 30.1; DPL- A- 18.2- 18.7; DA-C- 28.7- 30.7; DAD-C- 13.6-14.2; DRD- AD- 6.9-8.3; DAV- 5.1- 5.7; DVV- 13.2-14.2; HL (mm)- 19.0; HD- 61.4- 67.4; HW- 73.0- 75.0; DOST- 84.1- 85.8; DOD-52.6-54.5; LFG- 75.0- 76.3; LOP-34.2- 36.4; PORL-40.5-44.7; STL-31.8- 34.2; ED- 23.7- 30.0; IOW- 28.6- 33.7; INW-22.5-22.7; STL-31.8- 34.2; WGM-39.5-44.9; LMB- 343.0-367.0; LNB-73.0-77.0; LOMB-132136.8; LIMB- 90-94.7.

Other morphological characters: Median longitudinal groove on head narrow and moderately deep; it never reaches occiput; it is divided into two parts; first part is long and it extends up to a little behind outer margin of orbit; the second fontanel is spindle shaped. Occipital process reaches to basal bone of dorsal fin. nasal barbels just reach the base of occipital process; outer mandibulars reach considerably behind the middle point between pectoral and pelvic fin; near to ventral origin, one ED anterior to ventral origin; inner mandibulars extend considerably behind pectoral fin origin nearly to the middle of pectoral fin, when the latter is stretched to the body; maxillaries reach to or reach near to caudal base; outer mandibulars located outwards and backwards of inner mandibulars. posterior tip of rayed dorsal fin reaches considerably behind adipose fin front; dorsal fin long, its length nearly equal to body depth at dorsal fin origin; inter dorsal distance equals to snout length; Posterior base of adipose fin considerably behind the posterior most part of base of anal fin. Ventral fin tip just reaches or reach near to anal fin origin; Tips of caudal lobes pointed.

Colour: Back and lateral sides light blackish brown; ventral side and ventro-lateral sides whitish yellow; last anal ray divided to root; dorsal spine with 6 teeth from above the middle of dorsal spine; outer mandibulars reach behind pectoral tip, one eye diameter anterior to ventral origin; inner mandibulars reach considerably behind pectoral tip, a little greater than inter orbital width, from pectoral base.

Many scientists including Grant considered Mystusarmatus as a synonym of $M$. oculatus. But Plamoottil and Abraham resurrected the former from the synonymy of $M$. oculatus.

Distribution and habitat: Northern Kerala. Found in deep freshwater bodies.

\section{Mystus oculatus (Valenciennes)}

Bagrus oculatus Valenciennes [3], IN Cuvier, Valenciennes Hist Nat Poiss 14: 434 (type locality: Kuttiadi, Malabar).

Names: Regional names- Kotti, Chittan koori; common nameMalabar Mystus; synonyms- Bagrus oculatus, Macrones oculatus.

Diagnosis: Occipital process extends to basal bone of dorsal fin; median longitudinal groove on head extends to base of occipital process; eyes large and its diameter 33.0-40.0\% of HL. Maxillary barbels extend to middle of anal fin. A dark spot is present at the origin of rayed dorsal fin. Adipose fin small and located away from rayed dorsal fin. 9- 10 branched rays present in anal fin.

Meristic counts: D- I, 7; P- I, 8-9; V- i, 5; A- iii, 9-10; C- 17; DSPT2-8; PSPT- 12-14

Metric characters: TL (mm)- 111.0- 122.0; SL (mm)- 85.0- 91.0; \% SL: HL- 23.3- 25.6; HD- 16.0- 18.2; HW-15.1- 18.3; DD-20.9- 23.0; BDA-17.4- 19.2; BWD-15.5-16.7; BWA-10.0- 11.6; PRD-37.2- 37.8; POD-3.1- 66.2; PRP-22.0-26.1; PRPL- 47.1- 51.2; PRA- 68.1-75.6; LRD21.1- 23.6; LAD- 5.5-6.7; LP- 18.0-20.0; LPL- 13.9-15.6; LA- 13.0-15.1; LUCL- 29.1- 31.9; LLCL- 24.7- 26.7; LBRD- 14.0-15.3; LBAD- 17.219.0; LBA- 12.8-14.0; LBC- 11.8-13.9; LCP- 15.6-19.2; DCP- 10.6-11.6; WCP- 4.7-6.; DP-PL- 25.9- 30.8; DPL- A-19.8- 22.2; DA-C- 28.3- 31.4;
DAD-C- 16.1-18.0; DRD- AD- 16.5- 18.2; DAV- 6.0- 7.6; DVV- 14.415.9; HL (mm)- 20.0- 23.0; \% HL: HD- 66.0- 71; HW- 65.0- 71.7; DOST- 86.4- 95.0; DOD- 58.3- 66.5; LFG- 77.8- 89.5; LOP- 37.5- 40.5; PORL- 41.0- 45.6; STL- 26.0- 28.3; ED- 33.0- 40.0; IOW- 23.6- 27.5; INW- 16.0- 17.5; STL- 26.0- 28.3; WGM- 35.0- 41.3; LMB- 308.7322.7; LNB- 66.0- 70.0; LOMB- 122.6- 145.7; LIMB- 72.7- 90.0.

Other features: Posterior dorsal part of head rugose; median longitudinal groove divided into two; anterior portion wide and extend up to posterior margin of orbit; posterior fontanel shallow and narrow and extends to occiput. Anterior nostrils located at the tip of snout; mouth extends backwards behind the base of maxillary barbels; eyes large; interorbital distance equal to ED. Nasal barbels reach halfway between posterior margin of eye and occiput; it never reaches outer opercular margin or pectoral base; outer mandibulars reach a little behind half way between pectoral and pelvic fins; inner mandibulars reach pectoral fin base. Posterior base of adipose fin reaches just in front of posterior base of anal fin. Inter dorsal distance about 1.2 times in adipose dorsal fin base. None of fins touch each other. Colour: Silvery or yellowish on the flanks and darker on the dorsal region; abdomen whitish.

Distribution and Habitat: Kerala and Tamil Nadu. Found in deep freshwater rivers and estuaries.

\section{Mystus seengtee (Sykes)}

Pimelodus seengtee Sykes [21], 164 (type locality: Dukhun, India); Sykes, 1841: 374, Pl. 66.

Names: Regional name- kotti; common name: long whiskered Mystus; synonyms: Pimelodus seengtee, Bagrus cavasius.

Diagnosis: Maxillary barbels very long, reaching to caudal-fin base; a black spot present in front of the dorsal-spine base; adipose fin long based, dorsal spine short and feeble, a dark spot present on humeral region and body without distinct midlateral stripe.

Meristic counts: D-I, 7; P-I, 8; V-i, 5; A-iv, 9; C-15; DspT- Nil; PspT- 12-13.

TL (mm)- 157.5- 204.5; SL (mm)- 120.0-156.5; \% SL: HL- 22.124.2; HD- 14.9- 15.8; HW- 13.4-15.9; BDD- 20.3-22.7; BDA - 14.215.8; BWD- 13.8-14.5; BWA- 7.6- 8.3; PRD- 34.4-34.8; POD- 65.2-71.0; PRP-20.02- 20.8; PRPL-45.4- 49.0; PRA- 67.1- 70.9; LRD- 20.7-23.4; LAD- 5.5- 6.6; LP- 16.9-20.0; LPL- 15.3-16.7; LA- 13.5-16.7; LDSP13.7-15.9; LPSP- 13.4-14.8; LUCL- 30.3- 31.6; LLCL- 21.7-24.2; LBRD13.4-14.6; LBAD- 42.1-46.2; LBA- 9.2-10.3; LBC- 7.9-12.1; LCP- 19.222.4; DCP- 7.6-8.3; WCP- 3.6- 4.0; DP-PL-26.9- 28.9; DPL- A- 19.823.6; DA-C- 28.9-31.3; DAD-C- 9.5-10.3; DAV- 7.0-9.6; DVV- 13.316.3; HL (mm)- 29.0-35.0; HD- 65.6-68.8; HW- 60.9-71.4; DOST- 82.887.5; DOD- 60.3-71.9; LFG- 58.6-65.7; LOP- 60.3-71.9; PORL- 39.3 42.9; STL- 31.3-35.9; ED- 26.9-32.8; IOW- 21.9-31.4; INW- 14.6-15.6; STL- 31.3-35.9; WGM- 32.8-37.1; LMB- 382.8-443.8; LNB- 62.1-78.1; LOMB- 146.9-167.1; LIMB- 81.4-93.1.

Other features: Cephalic groove divided into two narrow fontanels; Posterior fontanelle extending to base of supraoccipital spine. The latter is elongated, slender and extending to anterior nuchal plate. Outer mandibluar barbels extending to middle of rayed dorsal fin; inner mandiblars extend to posterior most base of pectoral fin. Dorsal spine long, straight, slender and without distinct serrations. Pectoral spine stout and with 12- 13 strong teeth.

Color: Body silvery; pectoral, pelvic and anal fins hyaline; adipose fin dusky; rayed dorsal fin pale yellowish. 
Citation: Plamoottil M (2017) Taxonomic Notes on Mystus Species of Northern Kerala. J Aquac Res Development 8: 495. doi: 10.4172/21559546.1000495

Distribution and habitat: India. Found in shallow hill streams with rocky bottom.

\section{Conclusion}

Rivers of northern parts of Kerala are rich in finfish faunal resources; many rare and unnamed fish species residing in aquatic bodies of Wayanad and Trichur. Due to lack of sincere taxonomic studies a number of fish species described by Jerdon [4] and Day [5] from Wayanad and Trichur are still considered as synonyms of some available ones. Some recent new descriptions and redescriptions [2228] from this area are hopeful. It is expected that more taxonomic studies may be conducted on inland fishes of northern parts of Kerala in days to come.

Comparative materials examined are shown below:

Mystus seengtee: ZSI FF 4936, 4 ex., 120-156.5 mm SL, Koodal kadavu, Mananthavady River, Wayanadu, Kerala, collected by Mathews Plamoottil, 20.03.2013.

Mystus malabaricus: ZSI FF 4931, 5 ex., 71.5-102 mm SL, Kallodi, Mananthavady River, Wayanad, Kerala, collected by Mathews Plamoottil, 20.03.2013.

Mystus oculatus: ZSI FF 4933, 5 ex., 85-91 mm SL, Arattupuzha, Karavannoor River, Trichur, Kerala, collected by Mathews Plamoottil, 10.01.2013; ZSI 487, I ex., India, purchased from Francis Day.

Mystus armatus: ZSI FF 5095, 2 ex., Arattupuzha, Karavannoor River, Trichur, collected by Mathews Plamoottil, 13.01. 2013;

Mystus montanus: ZSI FF 5096, 1 ex., 67.5 mm SL, Koodal kadavu, Mananthavady River, Wayanad, collected by Mathews Plamoottil, 16.03.2013.

\section{Acknowledgement}

The author is grateful to reviewer's comments of which helped to improve the manuscript. The author acknowledges principal, Baby John Memorial Government College, Chavara, Kerala for providing the necessary facilities.

\section{References}

1. Mo T (1991) Anatomy and systematics of bagridae (Teleostei) and siluroid phylogeny. Koeltz, scientific books, Koenigstein, Germany.

2. Roberts TR (1994) Systematic revision of the Asian bagrid catfishes of the genus Mystus sensu stricto with a new species from Thailand and Cambodia. Ichthyol Explor Freshwat 5: 241-256.

3. Valenciennes MA (1839) Histoire naturalle Poissons, Paris.

4. Jerdon TC (1849) The fishes of Southern India. Madras J Lit \& Sc 15: 147.

5. Day F (1865) The fishes of Malabar. Bernard Quaritch, London.

6. Grant S (1999) A replacement name and neotype designation for Hara malabarica Day, 1865, with notes on related species. Aqua 3: 169-174.

7. Plamoottil M, Abraham NP (2013) Mystus indicus and M. heoki, two new cat fishes from Kerala, India. Biosystematica 7: 43-58.

8. Plamoottil M, Abraham NP (2013) Mystus menoni, a new fish species from Kerala, India. Int J Pure Appl Zool 1: 315-325.
9. Plamoottil M, Abraham NP (2014) Mystus keralai, a new fish species from Kerala, India. Int J Pure Appl Zool 2: 196-205.

10. Plamoottil M (2016) Mystus catapogon, a new fish species from Kerala, India JRB 6: 1967-1976.

11. Plamoottil M (2015) Taxonomic notes on the catfishes of central Travancore. $J$ Zool Biosci Res 2: 6-17.

12. Plamoottil M (2016) Systematic studies on the catfishes of Sasthamcottah lake of Kerala, India. Int J of Res Stud in Zool 2: 9-16.

13. Plamoottil M, Abraham NP (2012) Glyptothorax elankadensis, a new species of sisorid fish from Manimala River, Kerala, India. Biosystematica 6: 17-25.

14. Plamoottil M, Abraham NP (2013) Horabagrus melanosoma, a new fish species (Actinopterygii: Siluriformes) from Kerala, India. Int J Pure Appl Zoo 1: $280-288$.

15. Plamoottil M (2014) Batasio flavus, a new catfish from Kerala, India. JRB 3 74-76.

16. Plamoottil M, Abraham NP (2014) Rediscovery and redescription of Mystus armatus Day. Int J Res Fish Aqu 4: 18-21.

17. Day $F$ (1878) The fishes of India: Being a natural history of the fishes known to inhabit the seas and fresh waters of India, Burma, and Ceylon. Bernard Quaritch, Piccadilly, London.

18. Day F (1889) Fauna of British India including Ceylon and Burma. Taylor and Francis, London.

19. Jayaram KC (2002) Fundamentals of fish taxonomy. Narendra publishing House, Delhi.

20. Jayaram KC (2010) Fresh water fishes of the Indian region. Narendra publishing House, Delhi.

21. Sykes WH (1839) An account of the fishes of Dukhen in proceedings of learned societies, Zoological society. Ann Mag Nat Hist 6: 164.

22. Plamoottil M (2014) Pristolepis pentacantha, a new species of fish from Kerala, India. IJSR 3: 552-554

23. Plamoottil M (2014) Puntius nigronotus, a new fish species from Kerala, India. JRB 4: 1581-1588.

24. Plamoottil M (2015) Validation of Pristolepis pentacantha Plamoottil. Int J Pure Appl Zool 3: 142-143.

25. Plamoottil M (2016) Puntius euspilurus, a new fish species from Kerala, India Int J Res Stud Biosci 4: 1-6.

26. Plamoottil M (2017) Pristolepis procerus, a new fish species from Kerala, India. Euro J Zool Res 1: 40-44.

27. Plamoottil M (2013) Rediscovery of Pristolepis marginata Jerdon (Teleostei: Percomorpha: Pristolepididae) after one and a half century. Res J Animal Veterinary Fishery Sci 1: 1-5.

28. Plamoottil M, Abraham NP (2013) Rediscovery of Mastacembelus malabaricus after one and Half Century. Res J Animal Veterinary Fishery Sci 1: 6-11. 